\title{
Is the Shark Just Drifting, or Does It Take a Quick Nap?
}

\author{
Erich K. Ritter ${ }^{1,2}$ \\ ${ }^{1}$ Department of Mathematics and Statistics, University of West Florida, Pensacola, FL, USA \\ ${ }^{2}$ Shark Research Institute, Princeton, NJ, USA \\ Email: eritter@uwf.edu
}

How to cite this paper: Ritter, E.K. (2020) Is the Shark Just Drifting, or Does It Take a Quick Nap? Open Journal of Animal Sciences, 10, 40-47.

https://doi.org/10.4236/ojas.2020.101004

Received: September 4, 2019

Accepted: December 10, 2019

Published: December 13, 2019

Copyright $\odot 2020$ by author(s) and Scientific Research Publishing Inc. This work is licensed under the Creative Commons Attribution International License (CC BY 4.0).

\begin{abstract}
It is unknown if resting sharks can sleep, which is also true for gliding ones. Here, a videotaped bull shark is presented that drifted in an uncontrolled manner for 120 seconds while sinking with $0.1 \mathrm{~m} /$ second. Several aspects are discussed to determine if the shown behavior reflects the commonly accepted definition of sleep. Additionally, the idea is also discussed if this state might reflect a "quiet waking state" instead of where the shark still maintained some vigilance despite its general appearance.
\end{abstract}

\section{Keywords}

Drifting, Melatonin, Pineal Gland, Shark, Sleep

\section{Introduction}

Some shark species rest on the bottom for long periods [1] [2] [3], but it is uncertain if they sleep during these phases. Although some anecdotal evidence suggests that sharks may sleep [4], the definite proof has not been offered to date. Sleep has been established for some teleosts [5] [6] [7], and it is shown that their pineal gland is essential for sleep-related melatonin production [6] [8]. Sharks also possess a pineal gland, which would suggest that at least some shark species may sleep similarly to teleosts.

However, what about the sharks that continuously swim? Many of those species are known to glide [9] [10] [11], which saves energy [12] [13] and thus can also be interpreted as some form of rest. However, could this form of rest turn into some superficial sleep for short periods?

Here a non-directional and rather spatial gliding display of a mature female bull shark, Carcharhinus leucas, is described that lasted 120 seconds, during which the shark sank $12 \mathrm{~m}$. Due to the prominent sinking, this non-directional 
gliding could be seen as a form of undirected hovering that turned into drifting due to the sinking effect caused by the shark's weight.

Although gliding phases and connected vertical loss of depth have been shown [11] using dataloggers, this is the first direct observation of such a pattern, and it is used here to discuss the possibility that this non-directional drifting may not just reflect another form of gliding but may indicate some sleeping behavior.

\section{Methods and Results}

On February 15, 2019, a bull shark was observed at "TigerBeach," a site on the outer banks of the North-western Bahamas. The site's depth was about $13 \mathrm{~m}$, with a sandy bottom, mixed with patches of seagrass. The observation happened around $10 \mathrm{am}$, with a bright sky and no overcast. The observer was the only person left in the water at the end of a dive. The video was taken with a GoPro 7 in $2.7 \mathrm{~K}$ density and $100 \mathrm{fps}$.

The videotaped bull shark was part of a group of four sharks and the only shark swimming in the water column. The animal was observed for several minutes before taking the video. The other three sharks remained in the broader vicinity of the dive boat but entirely stayed at the bottom, no more than $1 \mathrm{~m}$ above ground. The female in question had a length of about $2.5 \mathrm{~m}$. Other sharks present at the site were a few Caribbean reef sharks, C. perezi, as well as lemon sharks, Negaprion brevirostris. The bull shark carried three sharksuckers, Echeneis naucrates, either attached to its body or swimming close by for the duration of the video.

The actual swimming speed of the shark in question could not be measured. Thus, possible speed changes during the observation were reflected by the tailbeat frequency [14] [15] [16].

The following description is divided into three phases, "ascending (pre-gliding)," "gliding," and "recovering."

A fourth paragraph, labeled encounters, describes the teleosts and two Caribbean reef sharks that either followed the bull shark or traversed her path at one point.

\subsection{Ascending (Pre-Gliding)}

The female swam up to the surface in a steep angle of about 45 degrees with a relative speed of 1 tailbeat/sec (Figure 1(a)), leveled off about $1 \mathrm{~m}$ below the surface, reducing her tailbeat to 0.4 tailbeat/sec, then ceased her activity and started gliding (Figure 1(b)). There was no visible target close to the surface. None of the present yellowtail snappers, Ocyurus chrysurus, or blue runners, Caranx crysos, that swam within $5 \mathrm{~m}$ off and in front of the shark adjusted their swim directions due to their closeness.

\subsection{Gliding}

As soon as the shark stopped actively moving, her caudal fin and both pectoral 


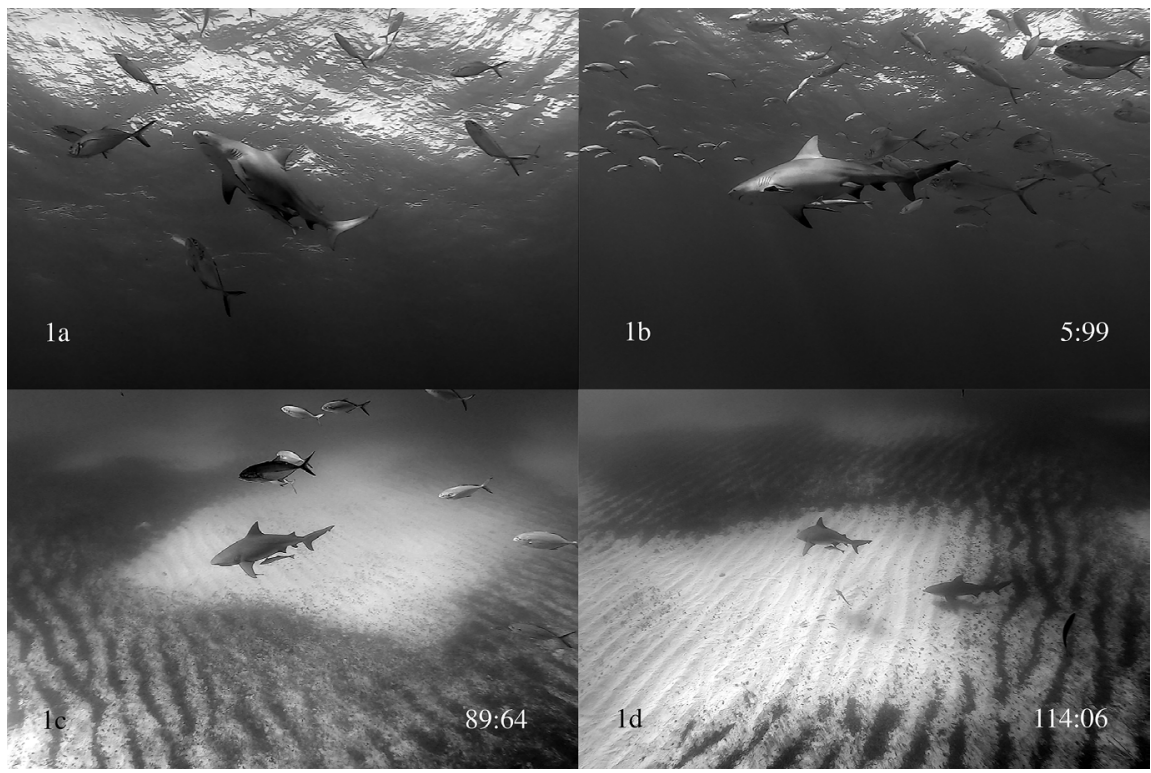

Figure 1. Different phases between ascending and gliding of the monitored bull shark. Numbers in the lower right corner reflect time after gliding started. (a) Ascending; (b, c) gliding; (d) Caribbean reef shark appears below the gliding bull shark.

fins dropped (Figure 1(b)), typical for gliding sharks [10]. The now relaxed tail kept swaying once in a while, based on the direction the body took. Once the gliding started, the shark quickly lost contact with the surface, in a non-directional pattern. The gliding went on for 120 seconds and ended right at the bottom. Within the duration of this passive display, the shark lost $12 \mathrm{~m}$ in vertical distance, which equals a loss of $0.1 \mathrm{~m} / \mathrm{sec}$.

The shark began the glide with a turn to the right, although there was no visible current (Figure 1(c)). The shark then continued to glide in that direction for 19 seconds, passively reversing to glide toward the left for 48 seconds before straightening out again and turning once more toward the right for the remainder of the glide.

\subsection{Recovering}

Once the shark was about $1 \mathrm{~m}$ from the bottom, one of the sharksuckers attached to the shark's underside abruptly moved while keeping contact with her body. This movement caused a quick shaking motion, called flickering [17], of the shark's right pectoral fin. This quick fin shaking did not lead her to start swimming again. A second flicker motion by the same pectoral fin, triggered by the same sharksucker, appeared to get the shark out of her hovering phase, albeit rather slowly with a relative swim speed of only 0.3 tailbeat/sec for the remainder of the video. At this point of starting to swim again, the shark's pectoral fins touched the bottom.

\subsection{Encounters}

Once the female bull shark started to glide, several rainbow runners appeared to 
check out the shark. Once the gliding phase was in progress, none of the teleosts following her. At the end of the gliding phase, a Caribbean reef shark traversed the path of the passively moving bull shark, but neither adapted their swim patterns or showed any response. A second Caribbean reef shark swam at the bottom (Figure 1(d)), behind and in the general direction of the bull shark at the end of her gliding phase. That shark veered off once it appeared that it would collide with the still uncontrolled gliding bull shark in front of it.

\section{Discussion}

Gliding has been shown for a variety of shark species, like e.g., white sharks, Carcharodon carcharias [18], whale sharks, Rhincodon typus [19], sand tiger sharks, Carcharias taurus [9], sevengill sharks, Notorhynchus cepedianus [20], lemon sharks [21], sandbar sharks, C. plumbeus [11], and others. Most free-swimming sharks seem to glide occasionally, but even species like the thresher shark, Alopias pelagicus, with extended gliding capabilities, does so primarily for shorter periods, is always direction oriented, either with or against the current, maintains depth, and does not sink in the process [10]. The movement pattern shown here is different and should be called drifting instead of gliding due to the non-directional path and the rather rapid sinking of the shark.

\subsection{Drifting}

The two most intriguing aspects of the presented display were the non-directional path the drifting female bull shark took and her quick sinking. Gliding sharks predominantly move in one direction, either with or against the current. Here, the shark drifted without any visible pattern, which could have been due to the lack of current. However, this would then raise the question of what caused her direction changes throughout the recorded phase without the involvement of her pectoral fins? Such changes could be due to minimal temperature, density, or salinity related differences causing small currents. However, a more plausible reason for the changing directions seems that the shark was indeed not gliding, but floating and her unequal bodyweight made it sink and drift in this uncontrolled way. Once she drifted, water flow around her body always changed, also creating vortices [22] [23], especially if she was not equally balanced, which could then translate into this random drifting.

Bull sharks occasionally glide, although typically for only a few seconds at a time, during which they remain level (pers. obs.). During these phases, they also seem to balance their position with small adjustments of their pectoral fins [24] [25]. Therefore, a loss of $0.1 \mathrm{~m} / \mathrm{sec}$ cannot be explained by a simple gliding effect. The relatively rapid loss implies that the hydrostatic lift of the shark did not compensate for her weight once active swimming stopped, and she was not using her pectoral fins to compensate [26] [27].

This combined circumstantial evidence offers the possibility that the bull shark fell into a short sleep-like state, which could explain both the rather quick 
sinking and the undirected drifting pattern.

\subsection{Characterization of Sleep}

There is general agreement that sleep in teleosts differs from inactivity when the fish, even if only for seconds at a time, shows 1) behavioral quiescence, 2) increased arousal threshold, and 3) homeostatic control [5] [6] [7]. The first two criteria are met in the case presented here. Homeostatic control, the need for sleep that increases with the time that is spent awake, cannot be determined, since sleep as such has not yet been suggested in bull sharks, or sharks in general, for that matter. It also remains unknown if bull sharks' swimming activities follow some circadian cycle, as known for other shark species [28] [29] [30], which would offer some evidence of homeostatic control.

Worth mentioning was the bull shark's reduced sensory responsiveness, a good indicator for sleep [31]. Even though the sharksucker caused the initial flicker motion on her right pectoral fin, it did not bring her out of her drifting stage, and it took a second flicker caused by the same sharksucker to prompt her to start swimming again finally.

Another evidence for a putative sleep-like state of this bull shark was her greatly reduced responsiveness during the entire drifting episode and especially when she got close to the bottom, as well as when a Caribbean reef shark traversed her path. Under ordinary circumstances, a Caribbean reef shark would increase its speed when traversing a bull shark's path that closely, but it did not do that in this case. Could it be that the Caribbean reef shark noticed the state the bull shark was in?

However, there is also the possibility that the shark was aware of its surroundings and was instead in a quiet waking state, as a substitute for an actual sleep state [31] [32]. For a free-swimming shark, a quiet wake state could be beneficial while it reduces its activity but still maintains vigilance. However, in a quiet waking state, the sharksucker's initial trigger could have been expected to create a stronger reaction than some flickering in her. Further, it would be anticipated that even a quietly alert shark would have started to correct her path before her pectoral fins touched the bottom.

\subsection{Pineal Glands}

Sharks possess pineal glands that produce melatonin [33]. Melatonin is the principal sleep-promoting agent in teleosts [34] [35] and also interacts with the hypocretin/orexin system, an essential sleep-wake modulator in some of those species [6] [8]. Whether sharks do possess an identical system is unknown, but it seems likely that the pineal gland produces related hormones for similar functions. Some resting sharks are lethargic during darkness, as observed for lemon sharks, grey reef sharks, C. amblyrhynchos, and whitetip reef sharks, Triaenodon obesus (pers. obs.). Further, circadian rhythms and cycles have already been shown for some shark species [28] [29] [30], making it likely that resting phases 
are also influenced by melatonin.

\subsection{Can a Single Event Be Relevant?}

Single observations, like the presented display, need to be treated carefully but can offer suggestions about functional aspects in the life of an animal [36] [37]. This video functions as a suggestion that even bull sharks, a species that has never been seen resting on the bottom, may have a mechanism that allows some form of rest, possibly even short-term sleep. At minimum, it shows that bull sharks can save energy through drifting.

\section{Conclusion}

The presented display of an uncontrolled drifting bull shark reflects the general aspects of sleep. Despite the single observation, the shark exhibits quiescence, with an increased threshold of arousal.

\section{Conflicts of Interest}

The author declares no conflicts of interest regarding the publication of this paper.

\section{References}

[1] Sazima, I. and Moura, R.L. (2000) Shark (Carcharhinus perezi), Cleaned by the Goby (Elacatinus randalli), at Fernando de Noronha Archipelago, Western South Atlantic. Copeia, 2000, 297-299. https://doi.org/10.1643/0045-8511(2000)2000[0297:SCPCBT]2.0.CO;2

[2] Peach, M.B. (2001) The Dorso-Lateral Pit Organs of the Port Jackson Shark Contribute Sensory Information for Rheotaxis. Journal of Fish Biology, 59, 696-704. https://doi.org/10.1111/j.1095-8649.2001.tb02373.x

[3] Ritter, E.K. and Amin, R. (2016) Mouth Cleaning of Lemon Sharks, Negaprion brevirostris, by Sharksuckers, Echeneis naucrates. Copeia, 104, 728-733. https://doi.org/10.1643/CE-16-431

[4] Clark, E. (1973) Sleeping Sharks in Mexico. Underwater Naturalist, 8, 4-7.

[5] Jones, R. (2007) Let Sleeping Zebrafish Lie: A New Model for Sleep Studies. PLoS Biology, 5, e281. https://doi.org/10.1371/journal.pbio.0050281

[6] Zhdanova, I.V. (2011) Sleep and Its Regulation in Zebrafish. Reviews in the Neurosciences, 22, 27-36. https://doi.org/10.1515/rns.2011.005

[7] Oikonomou, G. and Prober, D.A. (2017) Attacking Sleep from a New Angle: Contributions from Zebrafish. Current Opinion in Neurobiology, 44, 80-88.

https://doi.org/10.1016/j.conb.2017.03.009

[8] Appelbaum, L., Wang, G.X., Maro, G.S., Mori, R., Tovin, A., et al. (2009) Sleep-Wake Regulation and Hypocretin-Melatonin Interaction in Zebrafish. Proceedings of the National Academy of Sciences of the United States of America, 106, 21942-21947. https://doi.org/10.1073/pnas.906637106

[9] Tate, E.E., Anderson, P.A., Huber, D.R. and Berzins, I.K. (2013) Correlations of Swimming Patterns with Spinal Deformities in the Sand Tiger Shark, Carcharias taurus. International Journal of Comparative Psychology, 26, 75-82. 
[10] Ritter, E. (2014) Coasting of Pelagic Thresher Sharks, Alopias pelagicus, in Comparison to Two Other Species of the Same Ecomorphotype, and the Limitation of Video Capturing in Natural Settings. Environmental Sciences, 2, 13-23. https://doi.org/10.12988/es.2014.452

[11] Andrzejaczek, S., Gleiss, A.C., Pattiaratchi, C.B. and Meekan, M.G. (2018) First Insights into the Fine-Scale Movements of the Sandbar Shark, Carcharhinus plumbeus. Frontiers in Marine Science, 5, 483. https://doi.org/10.3389/fmars.2018.00483

[12] Weihs, D. (1973) Mechanically Efficient Swimming Techniques for Fish with Negative Buoyancy. Journal of Marine Research, 31, 194-209.

[13] Nakamura, I., Watanabe, Y.Y., Papastamatiou, Y.P., Sato, K. and Meyer, C.G. (2011) Yo-Yo Vertical Movements Suggest a Foraging Strategy for Tiger Sharks Galeocerdo cuvier. Marine Ecology Progress Series, 424, 237-246. https://doi.org/10.3354/meps08980

[14] Lowe, C.G., Holland, K.N. and Wolcott, T.G. (1998) A New Acoustic Tailbeat Transmitter for Fishes. Fisheries Research, 36, 275-283. https://doi.org/10.1016/S0165-7836(98)00109-X

[15] Graham, J.B., DeWar, H., Lai, N.C., Lowell, R.W. and Arce, S.M. (1990) Aspects of Shark Swimming Performance Determined Using a Large Water Tunnel. Journal of Experimental Biology, 151, 175-192.

[16] Scharold, J., Chin Lai, N., Lowell, W.R. and Graham, J.B. (1989) Metabolic Rate, Heart Rate, and Tailbeat Frequency during Sustained Swimming in the Leopard Shark Triakis semifasciata. Experimental Biology, 48, 223-230.

[17] Ritter, E. (2002) Analysis of Sharksucker, Echeneis naucrates, Induced Behavior Patterns in the Blacktip Shark, Carcharhinus limbatus. Environmental Biology of Fishes, 64, 111-115. https://doi.org/10.1023/A:1019642221755

[18] Del Raye, G., Jorgensen, S.J., Krumhansl, K., Ezcurra, J.M. and Block, B.A. (2013) Travelling Light: White Sharks (Carcharodon carcharias) Rely on Body Lipid Stores to Power Ocean-Basin Scale Migration. Proceedings of the Royal Society B: Biological Sciences, 280, Article ID: 20130836. https://doi.org/10.1098/rspb.2013.0836

[19] Gleiss, A.C., Norman, B. and Wilson, R.P. (2011) Moved by that Sinking Feeling: Variable Diving Geometry Underlies Movement Strategies in Whale Sharks. Functional Ecology, 25, 595-607. https://doi.org/10.1111/j.1365-2435.2010.01801.x

[20] Ebert, D.A. (1991) Observations on the Predatory Behaviour of the Sevengill Shark Notorynchus cepedianus. South African Journal of Marine Science, 11, 455-465. https://doi.org/10.2989/025776191784287637

[21] Motta, P.J. and Wilga, C.A.D. (1995) Anatomy of the Feeding Apparatus of the Lemon Shark, Negaprion brevirostris. Journal of Morphology, 226, 309-329. https://doi.org/10.1002/jmor.1052260307

[22] Zhu, Q., Wolfgang, M.J., Yue, D.K.P. and Triantafyllou, M.S. (2002) Three-Dimensional Flow Structures and Vorticity Control in Fish-Like Swimming, Journal of Fluid Mechanics, 468, 1-28. https://doi.org/10.1017/S002211200200143X

[23] Smith, T.H.E. and Caldwell, G.S. (2009) Computational Assessment of the Fluid Flow around Coasting Mature Male Blue Sharks, Prionace glauca (L.). Journal of Marine Biology, 2009, Article ID: 861590. https://doi.org/10.1155/2009/861590

[24] Wilga, C.D. and Lauder, G.V. (2000) Three-Dimensional Kinematics and Wake Structure of the Pectoral Fins during Locomotion in Leopard Sharks Triakis semifasciata. Journal of Experimental Biology, 203, 2261-2278.

[25] Wilga, C.A.D. and Lauder, G.V. (2004) Biomechanics of Locomotion in Sharks, 
Rays, and Chimeras. In: Carrier, J.C., Musick, J.A. and Heithaus, M.R., Eds., Biology of Sharks and Their Relatives, CRC Press, Boca Raton, FL, 139-164.

[26] Iosilevskii, G. and Papastamatiou, Y.P. (2016) Relations between Morphology, Buoyancy and Energetics of Requiem Sharks. Royal Society Open Science, 3, Article ID: 160406. https://doi.org/10.1098/rsos.160406

[27] Gleiss, A.C., Potvin, J. and Goldbogen, J.A. (2017) Physical Trade-Offs Shape the Evolution of Buoyancy Control in Sharks. Proceedings of the Royal Society B: Biological Sciences, 284, Article ID: 20171345. https://doi.org/10.1098/rspb.2017.1345

[28] Goldman, K.J., Anderson, S.D., Latour, R.J. and Musick, J.A. (2004) Homeothermy in Adult Salmon Sharks, Lamna ditropis. Environmental Biology of Fishes, 71, 403-411. https://doi.org/10.1007/s10641-004-6588-9

[29] Graham, R.T., Roberts, C.M. and Smart, J.C.R. (2005) Diving Behaviour of Whale Sharks in Relation to a Predictable Food Pulse. Journal of the Royal Society Interface, 3, 109-116. https://doi.org/10.1098/rsif.2005.0082

[30] Whitney, N.M., Papastamatiou, Y.P., Holland, K.N. and Lowe, C.G. (2007) Use of an Acceleration Data Logger to Measure Diel Activity Patterns in Captive Whitetip Reef Sharks, Triaenodon obesus. Aquatic Living Resources, 20, 299-305. https://doi.org/10.1051/alr:2008006

[31] Siegel, J.M. (2009) Do All Animals Sleep? Trends in Neurosciences, 31, 208-213. https://doi.org/10.1016/j.tins.2008.02.001

[32] Zimmerman, J.E., Naidoo, N., Raizen, D.M. and Pack, A.I. (2008) Conservation of Sleep: Insights from Non-Mammalian Model Systems. Trends in Neurosciences, 31, 371-376. https://doi.org/10.1016/j.tins.2008.05.001

[33] Claes, J.M. and Mallefet, J. (2011) Control of Luminescence from Lantern Shark (Etmopterus spinax) Photophores. Communicative \& Integrative Biology, 4, 251-253. https://doi.org/10.4161/cib.4.3.14888

[34] Wong, K.K.Y., Ng, S.Y.L., Lee, L.T.O., Ng, H.K.H. and Chow, B.K.C. (2011) Orexins and Their Receptors from Fish to Mammals: A Comparative Approach. General and Comparative Endocrinology, 171, 124-130. https://doi.org/10.1016/j.ygcen.2011.01.001

[35] Isorna, E., de Pedro, N., Valenciano, A.I., Alonso-Gómez, A.L. and Delgado, M.J. (2017) Interplay between the Endocrine and Circadian Systems in Fishes. Journal of Endocrinology, 232, 141-159. https://doi.org/10.1530/JOE-16-0330

[36] Ritter, E.K. (2012) A Rare Use of a Shark's Pectoral Fin? Scooping off a Sharksucker from the Flank. Open Fish Science Journal, 5, 57-59. https://doi.org/10.2174/1874401X01205010057

[37] Ritter, E. and Compagno, L.J.V. (2013) Clasper Flaring: Maintenance Behavior, or a Normally Hidden Feature of Male Whitetip Reef Sharks, Triaenodon obesus? Open Fish Science Journal, 6, 10-12. https://doi.org/10.2174/1874401X01306010010 